\title{
Lost and Found: Issues of Translating Japanophone Taiwanese Literature
}

\begin{abstract}
A high percentage of colonial Taiwanese literary works during the late Taishō period to the Shōwa period (1920-1946) was written in Japanese. To write in Japanese was not only a promising way to have works published in imperial Japan, but also provided a possible path for Taiwanese authors to reach a wider readership among Japanophone communities in East Asia. However, in the immediate post-war years, the body of Japanophone Taiwanese literature was "torn off” from Taiwanese literary history in the name of "decolonization." All publications in Japanese were abolished in Taiwan from 1946, and it was not until the lifting of the thirty-eight-year period of martial law that Japanophone Taiwanese literature was finally reintroduced to post-war Taiwanese generations in Chinese translation. This article will tackle the issues of how Japanophone Taiwanese literature was "translated back" into Chinese in order to reflect "authentic" Taiwanese culture. The translations of the Taiwanese writer Nao Weng's works will be used as examples, as his modernist literary representation is particularly worthy of scrutiny and highly challenging for translators to render "faithfully."
\end{abstract}

Keywords: Japanophone Taiwanese Literature, Minnanyu, Weng Nao, post-colonial translation, Taiwanese New Literature

\section{Introduction}

In the later years of Japanese colonial rule, ${ }^{1}$ literacy in the Japanese language was high in Taiwan due to the high percentage of attendance at the colonial public schools on the island (Matsunaga 1998, 332). In 1944, the last year of Japanese colonial rule, $71.17 \%$ of Chinese descendants (Hakka and Minnan people) and $83.38 \%$ of aboriginal children attended the Japanese public schools (Matsunaga 1998, 332). Colonial education had successfully solidified the status of Japanese in every area of life on the island, and having better (Japanese) language skills could therefore secure better career prospects for an individual. In the 1930s, the

1 Taiwan was ceded to Japan in the Treaty of Shimonoseki after Ch'ing China lost the First SinoJapanese War, and Taiwan was then under Japanese Colonial Rule from 1895 to 1945.

Ә Open Access. (C) 2020 Tzu-yu Lin, published by De Gruyter. (c) BY-NC-ND This work is licensed under a Creative Commons Attribution-NonCommercial-NoDerivatives 4.0 License. 
first generation of Taiwanese young adults who had completed the full compulsory colonial education were ready to express their thoughts in Japanese (Matsunaga 1998, 332). ${ }^{2}$ The prevalence of Japanophone writing on the island was, again, accelerated by the 1937 colonial law that all printed publications should be written in Japanese, and this produced an entire generation of Taiwanese authors who read and wrote in Japanese. For Taiwanese authors during the 1920s and 1930s, Japanese had become the major language for writing, and the influence of Japanese and Western literature (through Japanese translation) resulted in a boom of Taiwanese New Literature (Tarumi 1998, 3-4; Kleeman 2003, 194-195).

Taiwanese authors at the time also flocked to Japan, and sought every possible opportunity to have contact with Japanese authors, publishers, and readers in the hope of finding themselves a forum in the Japanophone literary field. It was important for Taiwanese authors to publish their work in Tokyo's publishing houses, as this would ensure that their works reached a wider readership among Japanophone communities in East Asia. In addition, it was a promising detour by which their works could make their way back to a Taiwanese readership in order to offer a different voice from those imported from imperial Japan. ${ }^{3}$ Many different types of anti-colonial associations were nurtured by the flourishing development of New Taiwanese Literature in Japanese. In this regard, the Japanese language no longer belonged exclusively to Japan; Japanophone Taiwanese literature had also become an important signature of diverse Taiwanese cultures and had come to bear Taiwan's colonial memory.

However, it was not until the martial law (1949-1987) which was announced by Chiang Kai-shek was brought to an end on the island that the younger Taiwanese generation learned of Taiwanese literature in Japanese. After a forty-year delay, in 1991 a collection of Taiwanese literary writing in Japanese was reintroduced to Taiwan's post-war generations in Chinese translation. Unlike the dilemmas of writing in the imperial or pre-colonial language, which are widely

2 The Japanese compulsory colonial education system began in 1896 (F. Chen 2011, 46).

3 The colonial authorities in Taiwan were authorized in 1897 to make laws according to the "specific" needs of ruling the Taiwanese people. People on the island lived in fear of being arrested and punished if the colonial authorities suspected that they were against the colonial government, so many anti-colonial societies and literary magazines were established in Tokyo in order to escape from the colonial laws on the island. Literary magazines, such as the Taiwanese People's Newspaper, were published in Tokyo and took a detour back to Taiwanese audiences (Chang 1985, 212). Ironically, for Taiwanese writers, Japan was a liberal destination for pursuing a literary career, as their works did not have to be closely examined by the colonial authorities on the island (Chang 1985, 129). 
discussed in post-colonial discourse, the case of Japanophone Taiwanese being translated "back" into Chinese, which has been widely considered as a "pre-colonial” language, seems to provide an extreme example of "returning." As most Taiwanese people of the post-war generations can no longer read the literature of their predecessors in its original language, they have to depend significantly on the translated texts in order to rediscover the literary production of this lost period in Taiwanese literary history.

When translating the cultural/historical context of Japanophone Taiwanese literature, translators are burdened with the heavy responsibility of transmitting cultural and historical memory while navigating the varying historico-political contexts of the Japanese colonial period and the Chinese Nationalist government's rule. This article will discuss what may have been gained or lost during the translation processes and investigate the different translation strategies of the translators, and the challenges that they faced during the process of negotiating between linguistic/cultural authorities. The translations of Weng's works will be used as examples since his contributions to modernist literary representation ${ }^{4}$ are especially challenging to translate "faithfully." The works included in the discussion are his poem "An Ode to the Bird" (1935), his novella Streets with a Port (1939), and his short story “A Stubborn Old Man” (1935). I will explore three different facets of Weng by discussing how and why his works have been translated in divergent ways.

\section{Three facets of Weng}

In translating Weng's works, each translator has his/her own preferences and concerns. The Sino-Taiwanese literary critic and translator Yang Xiang, for example, translates the poem "An Ode to the Bird” into archaic Chinese, which makes the piece read like an archaic Chinese poem. The Japanese translator Ai Sugimori translates Weng's Streets with a Port whilst maintaining some Japanese vocabulary in the translation. Still other Minnan-Taiwanese translators use Taiwanese

\footnotetext{
4 Among Taiwanese diasporic writers in Japan during the 1930s, Weng was well known as one of the few Taiwanese neosensualist writers in Tokyo. The Japanese modernist school of shin-kankakuha (neosensualism) was led by many major Japanese modernist writers, such as Yasunari Kawabata 川端康成 (1899-1972), Jun'ichirō Tanizaki 谷崎潤一郎 (1889-1965), Riichi Yokomitsu 橫 光利一 (1889-1947), Fumiko Hayashi 林芙美子 (1901-1947), and Waruo Sato 佐藤春夫 (18921964). Influenced by European modernism, neosensualism insisted on literary writing presenting the "primacy of aesthetics over politics or any other 'extra-literary' considerations" (Starrs 2011, 153-154).
} 
vernaculars to demonstrate Taiwaneseness in Weng's works. In the following sections, I will explore how these three different strategies are applied to translating Weng's works, and will discuss the ideologies behind these methods.

In his poem "An Ode to the Bird," Weng mixes kanji and katakana to create a sense of the antiquity of the Japanese language (Xiang 2009, 270). ${ }^{5}$ This kind of usage can be traced back to Japan's Heian period (AD 794-1192), and was mainly used by male authors, but it is no longer common in contemporary written Japanese, which is mainly composed in hiragana and kanji (Xiang 2009, 270). ${ }^{6}$ Weng's poetic language shows, in a way, his nostalgic affection toward old Japan, and also reinforces the idea of his preference for masculinist writing. ${ }^{7}$ Due to his familiarity with a foreign language (English) and katakana, Weng's poetic language ingeniously presents the double nature of the linguistic code system - the old and the new, the nostalgic and the modern, the authentic and the imported. Below is how Xiang translates this poem:

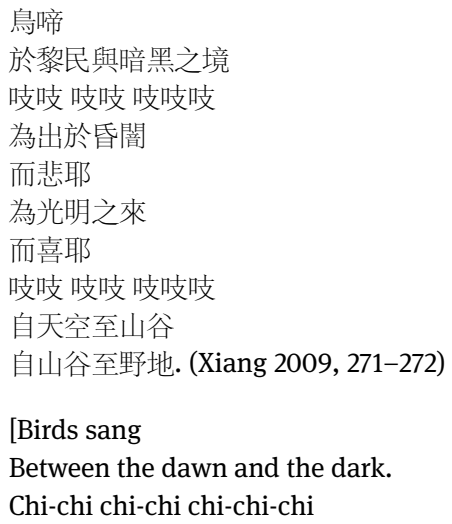

5 Kanji 漢字 were adapted from Chinese ideographs that were introduced by Buddhist monks from Korea. In using the adapted Chinese characters, the Japanese also made their own contributions and changes to their usage (Heisig 2008, 2, 4-5). Katakana 片仮名 is one of the three written systems and one of the two kana systems in Japanese. It is only used for foreign (except Chinese) loanwords, foreign names, foreign places, onomatopoeia, and words that depict psychological states or bodily feelings (Henshall 1990, 9-10). After westernization and modernization, much of Japanese vocabulary has been replaced by foreign expressions and imported words, and the use of katakana often conveys a sense of fashion and modernity (Haarmann 1989, 123).

6 Hiragana 平仮名 is one of the three writing systems and one of the two kana systems in Japanese. It is a Japanese syllabary, and is used for everything which is not written in katakana or kanji (Henshall 1990, 9).

7 His deferred modernist writing has followed European and Japanese masculinist writing in the hope of constructing the masculine identity of the author by objectifying female characters, as can be found in his works "Musical Clock," "Remaining Snow," and “A Love Story before Dawn." 
To fly out of the dark

Sad as they are.

To welcome the daylight

Delighted as they are.

Chi-chi chi-chi chi-chi-chi

From the sky to the valley

From the valley to the heath.] (my translation)

Xiang translates the first sentence of the original poem, 鳥八黎明卜暗黑卜ノ境 二啼夕 [Birds, between the dawn and the dark, sang] (Weng 1997, 21; my English translation), as 鳥啼 於黎明與暗黑之境 [Birds sang between the dawn and the dark] (my English translation), whilst another translator, Tsao-hsiang Chen (in Weng 1997, 18), translates it as 鳥兒, 牠在黎明與黑暗之際叫著 [Bird, it between the dawn and the dark, sang] (my English translation), which preserves the Japanese grammar and is closer to the original phrasing. In the original text and Chen's version, the subject, "the bird," comes first in the line and the verb, "sang," appears at the end, whilst in Xiang's version, the subject, "birds," and the verb, "sang," are put together at the beginning, which is in accord with the grammar of archaic Chinese. From the fourth line to the seventh line, Xiang's translation contains characteristically written poetic expression: he only uses sixteen words to translate 闇习出夕ノガ悲シイノカ光ガ來夕ノガ 嬉シイノカ [Out of the dark, so they are sad. Comes the light, so they are delighted] (Weng 1997, 21; my translation). The archaic word 闇 is used to mean "darkness" and "dimness," ${ }^{8}$ although it is more often replaced by the word 暗 today. Compared to Xiang's translation, Chen's translation is more oral and accords with the modern language used in Taiwan. Chen translates these four lines as 妳是否在悲泣? 悲 泣妳飛出了漆黑? 或是在高興? 高興妳迎接了光明? [Are you crying? Crying for your flying out of the darkness? Or are you delighted? Delighted for you are about to welcome the brightness?]" (in Weng 1997, 18; my English translation), which is eleven words longer than Xiang's version. ${ }^{9}$ Xiang also uses the archaic Chinese modal particle 耶, which was often used in archaic Chinese classics but rarely appears in modern Chinese poetry. In doing so, the original text has been transformed into an authentic Chinese poem.

Translating Japanophone Taiwanese literature into a piece of fully "authentic" Chinese literary writing was a very typical strategy, as it met the standard of publishing in Taiwan in the years immediately following the war. For translators who worked with literature from this specific period, writing across different cul-

8 It was used from the Zhou Dynasty (1045-256 BC) to the Han Dynasty (206 BC-AD 220).

9 Classical Chinese is usually shorter in its expression than the spoken language. 
tures usually involved compromise, since a translation of a text that reproduced rhetorical and authentic Chinese writing had a higher possibility of being accepted for publication. Although such a strategy has been challenged recently by some translators who prefer to translate Japanophone Taiwanese literature by using a hybrid Taiwanese language that is mixed with Japanese or Minnanyu, the prevailing strategy for translators is still that of standard Chinese translation, even decades after the end of martial law. Although a delicate translator, Xiang seems uninterested in passing on the memory of how a large group of Taiwanese intellectuals and Japanophone authors suffered from and fought against the oppression of the Chinese Nationalist government.

Chen, on the other hand, translates the poem by keeping the Japanese grammar in the original text. Although this does not cause any problems for comprehension by Taiwanese readers, it is very common for a translation like Chen's to be labelled a "bad" piece of translation, since the language used does not meet the standard of Chinese. In order to have their translations published, the older generation of translators would amend or soften the Japanese or Taiwanese identity of the original texts, otherwise the lines would be deleted by the editors at the publishing houses as it was thought that they might "offend" the Chinese Nationalist government. ${ }^{10}$ Therefore, the translators had to compromise if they wanted to reveal a hybrid Japanese-Taiwanese identity in their translations under political oppression.

The hybrid linguistic practice in the translation of Japanophone Taiwanese literature was not accepted until the 1990s. It might have been inspired by the Sinophone Taiwanese New Literature established by the Taiwanese author Huang Chun-ming in the 1960s. By using the modified hybrid language (which mixes Minnanyu and Japanese with Chinese) as his narrative language, Huang, strategically, does not only visualize the seemingly daily conversations of "minor" characters in narrating stories of everyday life in rural Taiwan, but also modifies his language into something that is understandable to general Sinophone readers who do not know Minnanyu. As Huang himself explains regarding his strategy of language use in the novels, the most difficult stage is to modify the languages used in the daily conversation of characters. Most of the characters in his novels speak only one language, that is, their mother tongue, Minnanyu; therefore, when transforming the street conversations from Minnanyu into Mandarin Chinese, as Huang points out, something may be lost during the process of modification since he cannot find the exact expressions in Chinese. However, Huang (1994) argues that this is still worthwhile since the modified hybrid language can enable more

10 Email correspondence with Prof. Liang-tse Chang in autumn 2011. 
readers who know nothing about Minnanyu to read his works without causing any confusion. Since Minnanyu is a language with eight intonations (four more than Mandarin Chinese), reading the conversations out loud, as Huang (1994) proposed in the article "A Young Literatus from Lotung," might be a good strategy for checking if the modified language still keeps the original flavour of Minnanyu. Widely recognized as a significant contribution to Taiwanese literature by prestigious Taiwanese scholars such as Fang-ming Chen and Bao-chai Jiang, Huang's experimental hybrid linguistic practice has shown a new post-colonial Taiwanese identity. The Taiwanese scholar Kuo-wei Chen $(2009,330)$ also agrees that such hybrid linguistic representation can indeed preserve the original flavour of Minnanyu - dialogue can be more vividly presented, and a sense of nostalgia can be created.

Following this trend, the translators of Weng's works, such as Chao-cheng Chung, Hsiao-nan Chen, and Ching-shiu Liao subscribe to the principle of hybrid linguistic literary representations established in this era. The dialogues in Weng's works set in rural Taiwan, such as "A Stubborn Old Man," "Little Lohan," and "Poor A-Jui," are translated using a hybrid language which has been mixed with Minnanyu and Mandarin Chinese in order to present the locality of the literature. For example, in “A Stubborn Old Man” Chao-cheng Chung translates A-Gim's speech 你說啥? 慣世跟阿足仔快轉來了呢[? ] Li kong shiah? Kuan-chi ka A-Tsua de ve den lai a ni[?] [What are you talking about? Kuan-chi and A-Tsu-a are coming back(?)] (in Weng 1991a, 23; my English translation) as mixed language (Mandarin Chinese and Minnanyu). In standard Mandarin Chinese, this sentence can be translated as 你說什麼? 慣世跟阿足快回來了嗎? Ni shuo she me? Kuan-shih ken A-Tsu kuai hui lai le ma? [What are you talking about? Kuan-shih and A-Tsu are returning?]. Instead of being translated into 什麼 she-ma, the question word has been translated into Minnanyu 啥 shiah, the informal word for 什, which contains only one syllable. Whilst in standard Mandarin Chinese 什麼 is a two-syllable phrase (she-ma), the tone of Minnanyu shiah is the fourth (shang-ru tone) of the eight tones; Mandarin Chinese only has four tones and one neutral tone, and she is the second tone (young-pin tone) and $m a$ is the neutral tone. In Minnanyu, shiah is short and ends with a stop, while in Mandarin Chinese the word she is pronounced as a long, flat sound with no stop at the end. This also shows the sound and the rhythm of Minnanyu in the conversation. Secondly, the names AGim, A-Chu-a, and A-Jui also reflect the special nickname system in Taiwan's Minnanyu communities. In order to show intimacy between friends and families, Taiwanese Minnan (nick)names are usually formed by adding an " $A$ " at the beginning of a name, and sometimes at the end of a name when the name is pronounced as a stop sound. The name 阿金 looks no different in Chinese characters, but the pronunciation is different. It is pronounced $A$-Chin in Mandarin Chi- 
nese and A-Gim in Taiwanese Minnanyu. ${ }^{11}$ Naming the characters according to the naming system of Minnanyu can thus show intimacy between the fictional characters and Taiwanese people. In addition, the verb 轉 in Mandarin Chinese means “turn,” but in Taiwanese Minnanyu it means “return.” So the verb phrase 轉來 can refer to "return" only when it is understood by a Taiwanese Minnanyu speaker. Lastly, the final particle 呢 ne, ni in the translation, which is relatively little used in Mandarin and should be replaced by the particle 嗎 $m a$ in such a context, is a featured pronunciation used at the end of the sentence in the everyday conversations of Minnanyu speakers in southern Taiwan. As analysed above, these features all reflect Taiwan's hybrid linguistic identity and its specific vernacular sound system.

Apart from that, the song sung by another character in the short story, A-Hui, is also in Taiwanese Minnanyu:

二十都過啦
還沟娶牽手咧
媒人婆仔
妳要把我怎麼樣
唉唷, 唉唷嘿. (Weng 1991a, 28)
[Twenty years old la
Not yet have a wife le
Matchmaker-a
What are you gonna do
Ai-yo, ai-yo-hay.] (my translation)

In the passage above, the phrase 牽手 kan chu means "wife" in Taiwanese Minnanyu, whilst in Mandarin Chinese 牽手 qian shou means "holding hands." The final particles, such as "la," "lei,” “a,” "ai-yo," “ai-yo-hay,” are used to show the rhythms and musicality of the Taiwanese vernacular.

The translation strategy employed in "Little Lohan," another of Weng's short stories which is also set in rural Taiwan, is to use Chinese quotation marks \lceil\rfloor - when it comes to Taiwanese vernacular language to show that the words are not used in standard Mandarin Chinese. For example:「輕便車」 “mobile car" (Taiwanese Minnanyu: kin-ban-chia; Japanese: kein-ben-shia) (Weng 1991b, 85), $\lceil$ 圓藍（音同「員林」）」 “round basket” (78), 「剃頭仔」 “barber” (82-83), 「火龍」 “fire dragon” (83), and「粿仔」 “rice noodles” (82).

11 There is no $m$ sound in the vocabulary of Mandarin Chinese, but it is frequently seen in Taiwanese Minnanyu. Also, the word begins with an alveolar in Mandarin Chinese but with a velar sound in Taiwanese Minnanyu. 
Nevertheless, Weng's literary language, as he himself claims, follows the principles of standard Japanese writing in order to allow a Japanese audience to be able to read his works, given that they might not have been familiar with the Taiwanese vernaculars and cultural context (“台灣文學當前諸問題 - 文聯東京 支部座談會” 1997, 225). Weng’s original intent of producing standard Japanese in his works cannot be seen in the translation - this is the cost of translating his works with a mixed language of Chinese and Minnanyu. The modification of his written language in order to make it read like Japanese literature rather than Taiwanese literature was an important tactic because he would not have wanted to limit his readership to the island of Taiwan. By doing so, he hoped he could gain access to the Japanese metropolitan literary field rather than being stereotyped as an author from colonial Taiwan. However, such an intention can no longer be discerned if the vast majority of his readership depends only on the translated texts.

In 2009, the Japanese scholar and translator Ai Sugimori offered a brand-new envisioning of Weng's work to Taiwanese readers in her translation of Streets with a Port. Her linguistic representation differs significantly from those of the older generation of translators. Thus far, it is the only work that has been translated by a Japanese translator, as the rest of Weng's texts have all been translated by Taiwanese translators.

Weng's final work, Streets with a Port, can be seen as representative of his multiculturalism and the mixture of literary influences from the West and the East. The story is set in the final year of Taishō Japan (1926) in the multicultural streets of the international Kōbe port, an area that was full of exotic nightclubs, bars, and cafés. Unlike Weng's earlier works, where the Taiwanese cultural context is threaded through the narratives, the central characters of this work are mainly Japanese and all the episodes happen in mainland Japan.

Sugimori's strategy in representing such "Japaneseness" in this work is to maintain some Japanese vocabulary in her translation. This strategy works well, since a great amount of Japanese vocabulary and expressions still remain in Taiwanese vernaculars, and some have already become standard in Taiwanese Chinese. Therefore, even though some Japanese words are not translated into Chinese, most Taiwanese readers can still understand the meaning. Sugimori keeps these words without translating them. For example, 料理店 “restaurant” can be understood by Taiwanese readers, as it still remains in Taiwanese Standard Chinese.

In addition, other original Japanese phrases and words are retained in translation, such as 雨後の简 “to mushroom like bamboo shoots after a spring rain” (Weng 2009, 308), ${ }^{12}$ 木棉 “cotton tree” (276), 阪妻 (a Japanese family name;

12 See the relevant entry in the online dictionary Ministry of Education (n.d.). 
234), 毛唐 “foreigners” (206), and 旅愁 “homesickness" (308). Some of the phrases are also used in Taiwan, such as 雨後の简 and 旅愁, while others are mainly Japanese. However, although the phrases and words mentioned above are in the same form - kanji (Chinese characters) - the meanings are different from Standard Taiwanese Chinese. For example, the original meaning of 雨後の简 is "to mushroom like bamboo shoots after a spring rain," as mentioned above, but was mistakenly taken by Weng as "outstanding and especially high among others” (2009, 309; my English translation). Another example is 木棉, which in Japanese means cotton in general, but in Taiwanese Chinese refers to a specific species - the cotton tree, which belongs to the same family but a different genus from cotton. This foreignizing strategy of keeping Weng's mistakes by using the wrong Chinese phrases and words creates an exotic element and sense of distance for Sinophone readers. Although this strategy might cause some confusion, Sugimori's translation of Weng's Streets with a Port can be seen as a significant development in the study of Weng's works, as her translation reveals the in-betweenness of Taiwanese linguistic and cultural identity (between Japan and China), which can hardly be found in any other earlier translation.

\section{Conclusion}

By discussing the three different facets of the translation of Weng's works, I have explored the questions of how Japanophone Taiwanese literary works have been reintroduced back to Taiwan, and elucidated connections between translation strategies and the influences of political ideologies. As the examples have shown, the choice to translate Weng's works into "authentic" Chinese or hybrid Taiwanese (mixed with Minnanyu) might be the outcome of the translators' ideological (un)consciousness, which reflects either the legacy of political oppression from the Chinese Nationalist government or the Minnancentred ideology in post-war Taiwan. The "rewriting" in these translations has therefore left traces of the earlier and current social and political values of post-war Taiwan. In this regard, each translation might not be able to "recall" the full memory that the author intended to convey in the original work, but it does show how the translators wanted future generations to "remember." Unlike Taiwanese translators who would never translate Weng's language with incorrect phrases or non-standard expressions, Sugimori's "imperfect" translation creates a sense of unauthentic Chineseness for Weng's work, which reflects the "foreignness" of colonial Taiwan and the awkward condition of Taiwanese cultural identity, which lies midway between Chinese and Japanese cultures/languages. 
Different translations of the same author's works reveal that different points of view and ideologies will always coexist. It is difficult to say which translator's achievements are greater than the others, as they all contribute to the intellectual development of the nation of post-war Taiwan. Certain versions will prove more successful in a certain time or in certain circumstances, and others in another time or circumstances. Only when all these versions are taken together and analysed in relation to each other will a rereading of the original texts from different perspectives be facilitated and the task of passing the colonial and cultural memory of Taiwan to future generations be fulfilled.

\section{Works cited}

“台灣文學當前諸問題 - 文聯東京支部座談會” [Issues in Taiwanese Literature - Notes on the Literary Association Tokyo Branch Conference]. 1936. Trans. Tsao-hsiang Chen陳藻香. 磺溪 文學 一翁鬧作品選集 [Huang-hsi Literature - Nao Weng's Literary Corpus]. Ed. Tsao-hsiang Chen 陳藻香 and Chun-ya Hsu 許俊雅. Chang-hua City: Chang-hua County Cultural Affairs Bureau, 1997. 221-236.

Chang, Su-chen 張素貞. “五O年代臺灣新文學運動” [New Taiwanese Literary Movement in the 50s]. 中外文學 [Chung Wai Literary Quarterly] 14.1 (1985): 129-146.

Chen, Fang-ming 陳芳明. 台灣新文學史上 [A History of Modern Taiwanese Literature. Vol. 1]. Taipei: Liking Books, 2011.

Chen, Kuo-wei 陳國偉. “借火攻火 - 黃春明小說中現代主義與民族主義的位移” [Fight Fire with Fire: The Switch of Modernism and Nationalism in Chun-ming Huang's Novels]. 泥土的滋 味：黃春明文學論集 [The Smell of the Mud: Analysis of Chun-ming Huang's Works]. Ed. Bao-chai Jiang 江寶釷 and Chen-shan Lin 林鎮山. Taipei: Lien-he wen-hsüeh, 2009. 320-351.

Haarmann, Harald. Symbolic Values of Foreign Language Use: From the Japanese Case to a General Sociolinguistic Perspective. Berlin and New York: Mouton De Gruyter, 1989.

Heisig, James W. Remembering the Kanji. 1977. Vol. 1. 5th ed. Hawaii: University of Hawai'i Press, 2008.

Henshall, Kenneth G., with Tetsuo Takagaki. A Guide to Learning Hiragana and Katakana: First Steps to Reading and Writing Japanese. Tokyo: Tuttle, 1990.

Huang, Chun-ming 黄春明. “羅東來的文學青年” [A Young Literatus from Lotong]. 從四 $O$ 年代到九 $O$ 年代: 兩岸三邊華文小說研討會論文集 [From the 40s to the 90s: Conference on Sinophone Fictions in China, Taiwan, and Hong Kong]. Ed. Tse Yang 楊澤. Taipei: China Times, 1994. 242.

Kleeman, Faye Yuan. Under an Imperial Sun: Japanese Colonial Literature of Taiwan and the South. 2003.

Matsunaga, Masayoshi 松永正義. “台湾の日本語文学と台湾語文学” [Japanophone Taiwanese Literature and Taiwanese Vernacular Literature]. 一橋論叢 [The Hitotsubashi Review] 119.3 (1998): 326-343.

Ministry of Education, R. O. C. (Taiwan). Online Dictionary. n.d. http://dict.revised.moe.edu.tw/ cgi-bin/cbdic/gsweb.cgi (1 January 2019).

Starrs, Roy. Modernism and Japanese Culture. London: Palgrave Macmillan, 2011. 
Tarumi, Chie 垂水千惠. 台灣的日本語文學 [Japanophone Taiwanese Literature]. Trans. Ts'ui-hua T'u 涂翠花. Taipei: Ch'ien-wei, 1998.

Weng, Nao 翁鬧. “競伯仔” [A Stubborn Old Man]. 1935. Trans. Chao-cheng Chung 鍾肇政. 台灣作 家全集：翁鬧、巫永福、王永雄合集 [Taiwanese Authors Series: Selected Works from Nao Weng, Yung-fu Wu, and Ch'ang-hsiung Wang]. Ed. Heng-hao Chang 張恆豪. Taipei: Ch'ienwei, 1991a. 21-49.

Weng, Nao 翁鬧. “羅漢腳” [Little Lohan]. 1935. Trans. Hsiao-nan Cheng 陳曉南. 台灣作家全集: 翁鬧、巫永福、王永雄合集 [Taiwanese Authors Series: Selected Works from Nao Weng, Yung-fu Wu, and Ch'ang-hsiung Wang]. Ed. Heng-hao Chang 張恆豪. Taipei: Ch'ien-wei, 1991b. 77-89.

Weng, Nao 翁鬧. “鳥ノ歌” [An Old to Bird]. 1935. 磺溪文學 一 翁鬧作品選集 [Huang-hsi Literature - Nao Weng's Literary Corpus]. Ed. Tsao-hsiang Chen 陳藻香 and Chun-ya Hsu 許俊雅. Chang-hua City: Chang-hua County Cultural Affairs Bureau, 1997. 21-23.

Weng, Nao 翁鬧. 有港口的街市 [Streets with a Port]. 1939. Trans. Ai Sugimori 杉森藍. Taichung: Morningstar, 2009.

Xiang, Yang 向陽. “幻影與真實 - 翁鬧詩作翻譯符碼的「演繹」與「延異」” [Phantom and Reality - the "Deduction" and the "Différence" of the Semiosis in the Translations of Nao Weng’s Poems]. 翁鬧的世界 [Nao Weng’s World]. Ed. Hsiao Hsiao 蕭蕭 and Hsien-jen Ch'en 陳憲仁. Taichung City: Morningstar, 2009. 251-277.

Tzu-yu Lin is a British Academy Postdoctoral Fellow in Translation at University College London, UK. She also works as the Script Consultant and Translator for the National Taichung Theater, the Taipei Children's Art Festival, and the Weiwuying National Kaohsiung Center for the Arts in Taiwan. Her research interests include comparative literary studies, translation studies, and memory studies. 